\title{
Measuring the Acceptance of Using Enterprise Resource Planning (ERP) System in Private Jordanian Universities Using TAM Model
}

\author{
Ahmad Althunibat, Ali Ahmad Zahrawi, Abdelfattah A. Tamimi, and Feras Hamed Altarawneh
}

\begin{abstract}
Enterprise resource planning (ERP) systems play very significant role in automated business processes. However, Private Jordanian universities should think more about implementing ERP systems to manage their processes and produce high quality output. Certainly, many research on ERP adoption have revealed that the organizations often faced many barriers and the failure rate is very high. In addition, different research projects conclude that, oftentimes, universities do not gain the expected benefits from adoption the ERP system. The universities in Jordan should understand the factors that affect the acceptance of ERP in order to gain the expect benefits of ERP. Hence, it is significant to determine the factors affect the acceptance of ERP in Jordanian Universities. The main objective of this research is to determine the factors that affect the acceptance of using ERP by Jordanian universities.
\end{abstract}

Index Terms-Acceptance, enterprise resource planning, higher education institutions, ERP adoption, TAM model.

\section{INTRODUCTION}

The use of new information and communication technologies (ICT) allows organizations to improve their internal and external communication by gaining speed, capacity, simplicity, and precision, which in turn increases the efficiency and effectiveness. In public administration, the use of ICT to provide services and improve management is not new, but since the 1990s, the use of ICT has reached high degrees of interest and demand, especially the Internet based technologies.

Enterprise resource planning (ERP) is a comprehensive integrated information system containing numerous configurable modules to automate the flow of resources among all the functions within an organization on a common database [1].

Experience has shown that the adoption of new information system is not enough to guarantee the benefits of using this system in organizations. Indeed, many researches on ERP adoption have revealed that the organizations often faced many barriers and the failure rate of ERP projects is very high. Furthermore, different research projects conclude that, oftentimes, universities do not gain the expected benefits from

Manuscript received November 14, 2018; revised May 15, 2019

Ahmad Thunibat, Abdelfattah A. Tamimi Thunibat, and Feras Hamed Altarawneh are with Software Engineering Department, Faculty of Science and IT, Al-Zaytoonah University of Jordan, Amman, Jordan (e-mail: a.thunibat@zuj.edu.jo,drtamimi@zuj.edu.jo,f.altrawenh@zuj.edu.jo).

Ali A. Zahrawi is with Management Information System Department, Faculty of Information Technology and Computer Science, Yarmouk University, Irbid, Jordan (e-mail: ali.z@yu.edu.jo). adoption the ERP system.

According to the study of Karande and Chakraborty [1], ERP providers or developers should understand the factors that motivate the organizations to adopt ERP system in order to enhance and improve their performance. Evaluation of acceptance factors may help organizations in understanding the potential of using ERP.

It can also motivate them to make a choice and to better utilized the services of ERP system [2]. Hence, it is significant to determine whether the universities in Jordan are prepared for implementing it. However, the introduction of new technologies and/ or systems leads to the emergence of new practices and, consequently, new requirements for more technological support. Moreover, in the case of using the ERP system in a variety of practices, there is little evidence on the convergence of practices.

The main objective of this research is to determine the factors that affect the acceptance of using ERP by Jordanian universities.

\section{ERP IN JORDAN}

The ERP system implantation in Jordan is still in early stages, and the industrial institutions adopted the ERP system before the education institutions. It is necessary to identify whether the Jordan culture and way of doing business may have a different impact on the implementation [3].

According to [3], the high cost of ERP implementation and high cost of consultants hinder the organizations in Jordan to adopt this technology and they argued that the ERP system can't be adopted without the support of institutional, social, cultural, and technological factors. Information quality and service quality have a significant impact on ERP acceptance [4].

The ERP system give the private universities in Jordan competitive advantages. An integrated database shared by different departments and different modules of ERP system cover all functions and management process of university can be a key for successful and competitive business.

Risks associated to the adoption of ERP systems in universities are very high, since many universities not aware about these risk this will be a major challenge to adopt the ERP System [5], [6].

To motivate and enhance the adoption of successfully implemented ERP projects university environment the initiators have to create a good environments for a successful cooperation between two type of stakeholders: the high management of a university, who is some time not familiar 
with ERP systems and their adoption benefits and development, and the developers, who do not have experience related to the implementation of ERP system for academic purposes on the other hand [5].

To generate the needed benefits form ERP system the business processes of the university must be aligned with those embedded in the ERP. If there is no alignment, the university will have to adapt its processes to those of the ERP. Such an adaptation often entails significant risks. Because processes embedded in an ERP are highly integrated, the degree of integration of a university's operational and managerial processes contributes to its readiness to implement this type of system.

\section{ERP ACCEPTANCE}

User acceptance can be described as a product of user behaviour in relation to the available technology and a given environment. Davis (1989) [7] has described, perceived usefulness and perceived ease of use as the main influences on user acceptance of information technology. As a consequence thereof, to achieve user acceptance the development of these perceptions need to be dealt with. Methods in this field range from standard quantitative approaches such as simply asking about how services would be or are perceived to explorative approaches of shadowing users.

There is a huge number of research paper which examines user acceptance of new technology, but only a few are studied the acceptance of ERP system in Jordanian universities. Different models and theories are available that attempt to describe the relationship of user's intention to use and beliefs in the use of technology. These models include the Theory of Reasoned Action (TRA), the Theory of Planned Behaviour (TPB), Unified Theory of Acceptance and Use (UTAUT), Diffusion of Innovations Theory (DOI), web trust model and the Technology Acceptance Model (TAM). Among these, TAM is considered to be the most widely accepted model because of its parsimony and the wealth of recent empirical support. TAM posits that perceived usefulness (PU) and perceived ease of use (PEOU) of Information Technology (IT) are major determinants of its usage. Therefore, this section discusses the concepts of acceptance models and theories and describes the proposed ERP acceptance model in the context of in Jordanian universities.

\section{TeChNOlOgy ACCEPTANCE MOdel (TAM)}

TAM was proposed by Davis (1989) [7] that constitutes two important concepts such as: perceived usefulness (PU) and perceived ease of use (PEOU) (see Figure 1). The PU refers the degree to which an individual believes that, using a particular system would enhance his/her job performance. The PEOU refers the degree to which an individual believes that, using a particular system would be free of physical and mental efforts.

In TAM, an individual's belief determines the attitude towards using the system and, in turn, the attitude helps to develop the intention to use. TAM is an adaptation of the Theory of Reasoned Action (TRA) which was developed by
Ajzan [8]. Comparatively, TRA is more generic whereas TAM is more specific. This study has chosen TAM due to two main reasons. First, TAM is based on its predictive power which makes it easy to apply in different information system devices. Second, TAM helps to better understand the relationship between four important constructs of the study; perceived usefulness, perceived ease of use, attitude and behavioural intention.

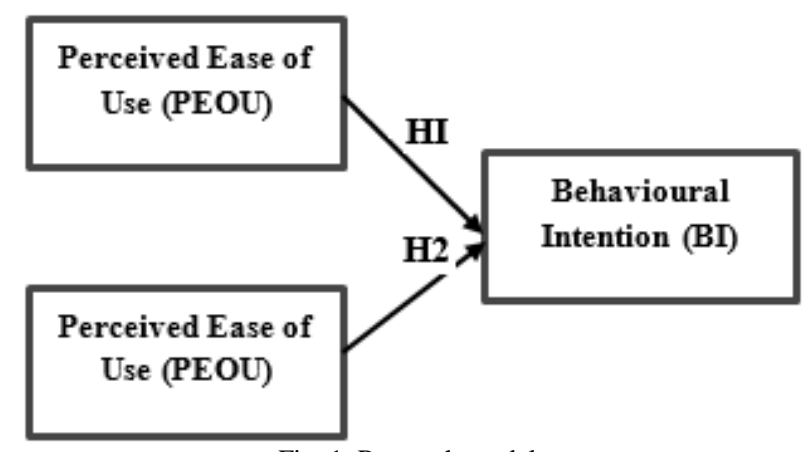

Fig. 1. Research model.

\section{RESEARCH METHODOLOGY}

The proposed methodology is presented in this section. Quantitative survey method was selected as shown in Fig. 2 in order to achieve the questionnaire objectives. The following sections will discuss the adapted methodology to carry out this questionnaire.

\section{A. Data Collection Techniques}

Online and by hand techniques, questionnaire data collection instruments have been deployed to collect the required data for this survey. The online survey was conducted through website, while the by hand questionnaire was distributed by mail.

The universities covered by the questionnaire were selected based on analysing the number of employees, faculties and the ranking. The analysis focused on the private universities that have abandoned ERP systems adoption. Therefore, as results to this analysis, ten universities were selected out of 28 in Jordan [9].

The sample size of this questionnaire has been calculated for each university separately. This is due to the disparity of the population for each university.

According to Olofssion et al. [10], the sampling methods of selecting respondents from the population such as (simple random, systematic and stratified sampling technique) were considered in order to obtain the required representative sample from the population. In term of this questionnaire, a simple random technique was adopted to select the participant from the population.

Online questionnaire sent to 500 university lecturers and mangers through website, out of the 500 sets of survey instrument distributed, 220 usable responses were received from ten universities, the response rates among universities were limited to between $30.83 \%$ and $50.32 \%$. According to Denscombe [11], the response rate of $20 \%$ to $25 \%$ can be considered as normal and can be accepted for online mailed questionnaires. Hence, the response rate of this study can be considered reasonable for the data analysis. The total number 
of respondents was 220 that have covered ten universities in Jordan.

\section{B. Questionnaire Design}

The questionnaire designed for the research comprises of close-ended questions. The close-ended questions enabled and facilitated easy coding and analysis. The questionnaire has two sections as follows: demographic information about the respondent and model items.

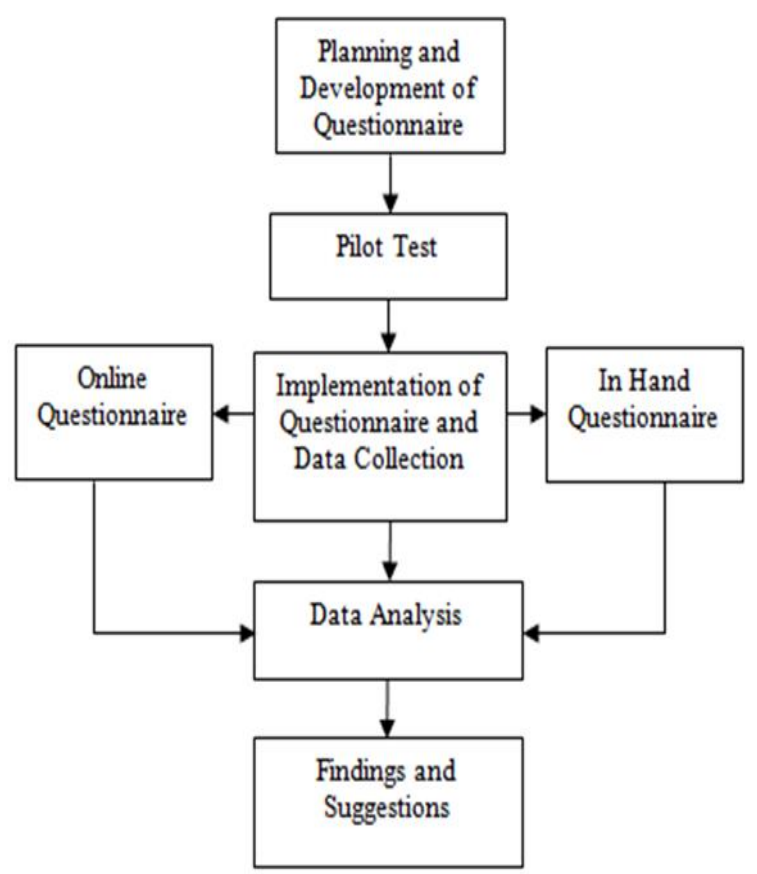

Fig 2. Research method.

The 9 questionnaire items were adapted from the earlier studies [3]. These items measured the model constructs that proposed in this study. Some modifications on items done to make them suitable for this research and fit the ERP acceptance research. The items were measured using a five point Likert scale, where $1=$ strongly disagree, $2=$ disagree, 3 $=$ neutral (neither disagree nor agree), $4=$ agree, $5=$ strongly agree.

The questionnaire was distributed by email to 30 of university lecturers, participated lecturers were randomly chosen from different ten universities. The data gathered was used for pilot study [7].the participated lecturers found that the questionnaire good organized and easy to fill.

One of the limitations of this survey is that some of the respondents found it difficult to understand the ERP terms mentioned in the questionnaire, as a result, some of the questionnaires were not completed and some were improperly completed.

\section{RESULTS}

To ensure the validity of the proposed model constructs reliability and validity testing are used. The results shows that the instrument's items are valid and there is a good consistency and reliability between them (see Table I) [12]. Since there is one dependent variable in the proposed model, the hypotheses were tested using linear regression analysis. Moreover, linear regression is very suitable analysis technique for testing the model; [8].

TABLE I: NTERNAL FACTOR RELIABILITY By CRONBACH’S ALPHA TECHNIQUE

\begin{tabular}{ll}
\hline \hline Construct & Cronbach's Alpha \\
\hline PU & .85 \\
BI & .87 \\
PEOU & .86 \\
\hline \hline
\end{tabular}

Also the demographic data of the participants were analyzed (see Table II).

TABLE II: DEMOGRAPHIC DATA

\begin{tabular}{|c|c|}
\hline $\begin{array}{l}\text { Sample } \\
\text { Characteristics }\end{array}$ & Results \\
\hline Academic & From 1 to 2 year $10.2 \%$ \\
\hline \multirow[t]{3}{*}{ experience } & From 2 to $535.00 \%$ \\
\hline & From 5 to $1040.7 \%$ \\
\hline & Above $10 \quad 14.1 \%$ \\
\hline \multirow[t]{2}{*}{ Gender } & Male $65.27 \%$ \\
\hline & Female $34.73 \%$ \\
\hline Age & Mean 35.10 \\
\hline Application & None $70.2 \%$ \\
\hline \multirow[t]{2}{*}{ Experience } & $1-2$ years $20.6 \%$ \\
\hline & More than 2 years $9.2 \%$ \\
\hline Application & None $91.4 \%$ \\
\hline \multirow[t]{2}{*}{ Training } & 1-20 Hours $5.2 \%$ \\
\hline & More than 20 Hours $3.4 \%$ \\
\hline
\end{tabular}

The regression analysis used to test the following hypotheses:

H1: "Perceived Ease of Use (PEOU)" has Significant impact on behavioural intention of using ERP in Jordanian universities.

H2: "Perceived Usefulness (PU)", has Significant impact on behavioural intention of using ERP in Jordanian universities.

Table III presents regression variables. The results show that, determinants of BI - PEOU and PU - were found to be significant in predicting perceived BI of ERP system.

TABLE III: REGRESSION MODEL ANALYSIS (BI) DEPENDENT VARIABLE

\begin{tabular}{llllll}
\hline \hline & \multicolumn{2}{l}{ Unst Coefficients } & $\begin{array}{l}\text { St } \\
\text { Coefficients }\end{array}$ & $t$ & Sig. \\
& B & Std. Error & Beta & & \\
\hline PU & .263 & .062 & .241 & .456 & .000 \\
PEOU & .251 & .050 & .230 & .434 & .000 \\
\hline \hline
\end{tabular}

Dependent Variable: BI $(F=192.348, P<=.001, R=.641, R$ Square= $=562$,

the best Predictor: PU (Beta $=-.456, P<.001)$

The proposed model $\left(\mathrm{R}^{2}\right)$ value for the dependent variable $\mathrm{BI}$ is 0.562 , which means $56.2 \%$ of the variance in $\mathrm{BI}$ is explained by the proposed model. This means that the power of the regression model is good. The model is statistically significant $(F=192.348, p<.001)$. Thus, the regression model supports the research hypotheses.

The results showed that the acceptance of ERP system among Jordanian universities were determined by two factors: The PU refers the degree to which an individual believes that, using a particular system would enhance his/her job performance. The PEOU refers the degree to which an individual believes that, using a particular system would be free of physical and mental efforts. . Among these two factors, PU was found to have the strongest influence on adoption; and positively affect user's intention to accept ERP system. 


\section{CONCLUSIONS AND FUTURE WORK}

The research model has been proved useful to draw profiles of Jordanian universities in terms of their intention to adopting ERP. While the model suggests that two factors play a significant role in explaining the universities willingness to adopt an ERP. This study had adopted the TAM acceptance model of ERP in Jordanian universities based on the quantitative approach. The results of this questionnaire have revealed the factors that affect the acceptance of ERP by the universities in Jordan.

ERP systems were firstly utilised by manufacturing sectors. With the development of ERP systems, Jordanian universities have to organise and standardise their business activities to reap the benefits of utilizing ERP system. In order to adopt the ERP systems the organization should measure their readiness to utilize these systems. In this study we focused on measuring Jordanian universities intention to adopt ERP, hence this study is very important for HEI to take the decision to adopt ERP and find the weakness factors that hinder the adoption process.

There are many suggestions for future work the most interesting one is to explore further into the factors that prevent the HEI from adopting ERP systems. Hence this study conducted in Jordanian Universities. Similar research efforts can be applied to different universities in different countries.

\section{REFERENCES}

[1] P. Karande and S. Chakraborty, "A fuzzy-MOORA approach for ERP system selection," Decision Science Letters, vol. 1, no. 1, pp.11-21, 2012.

[2] Z. A. Hasibuan and G. R Dantes, "Priority of key success factors (KSFS) on enterprise resource planning (ERP) system implementation life cycle," Journal of Enterprise Resource Planning Studies, p. 1, 2012.

[3] M. Nassar, L. Warrad, and Y. A. Siam, "The implementation of enterprise resource planning system within Jordanian industrial sector," International Review of Management and Marketing, ISSN: 2146-4405, vol. 7, no. 3, 2017.

[4] E. Abu-Shanab, R. Abu-Shehab, and M. Khairallah, "Critical success factors for ERP implementation: The case of Jordan," The International Arab Journal of e-Technology, vol. 4, no. 1, pp. 1-7, 2015.

[5] S. Rani, "A review of ERP implementation in higher education institutions (2016)," International Journal of Advanced Research in Computer Science and Software Engineering, vol. 6, no. 6.
[6] A. Ahmad, N. A. M. Zain, and N. Sahari, "The effect of social influence on mobile governmt adoption in Malaysia," Journal of Theoretical \& Applied Information Technology, vol. 25, no. 2, 2011.

[7] F. D. Davis, "Perceived usefulness, perceived ease of use, and user acceptance of information technology," MIS Quarterly, pp. 319-340, 1989.

[8] I. Ajzen, "The theory of planned behavior. Organizational behavior and human decision processes," 1991.

[9] P. Olofsson, G. M. Foody, M. Herold, S. V. Stehman, C. E. Woodcock, and M. A. Wulder, "Good practices for estimating area and assessing accuracy of land change," Remote Sensing of Environment, vol. 148, pp. 42-57, 2014.

[10] M. Denscombe, The Good Research Guide: For Small-Scale Social Research Projects, McGraw-Hill Education (UK), 2014.

[11] D. Gefen, E. Karahanna, and D. W. Straub, "Trust and TAM in online shopping: An integrated model," MIS Quarterly, vol. 27, no. 1, pp. 51-90, 2003 .

[12] A. Althunibat, "Determining the factors influencing students' intention to use m-learning in Jordan higher education," Computers in Human Behavior, 2015.

Copyright $@ 2019$ by the authors. This is an open access article distributed under the Creative Commons Attribution License which permits unrestricted use, distribution, and reproduction in any medium, provided the original work is properly cited (CC BY 4.0).

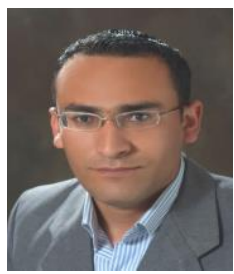

Ahmad Thunibat now works as the head of Software Engineering Department at Al-Zaytoonah University of Jordan, Amman, Jordan.

$\mathrm{He}$ obtained his $\mathrm{PhD}$ degree in software engineering from the National University of Malaysia in 2012. His research interests include software testing, information systems acceptance, requirement engineering, mobile technology.

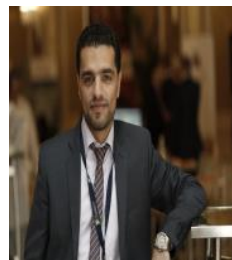

Ali A. Zahrawi is currently an assistant professor in the Department of Management Information Systems in the Faculty of Information Technology and Computer Science at Yarmouk University, Irbid, Jordan. He received his $\mathrm{PhD}$ degree in systems science and management in 2012 from the National University of Malaysia. His research interests include information systems testing, ERP systems, knowledge management and e-learning.

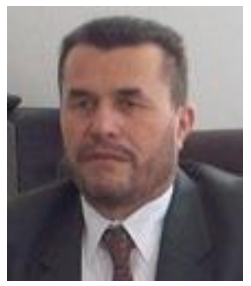

Abdelfattah A. Tamimi now works as the dean of Faculty of Science and information Technology at Al-Zaytoonah University of Jordan, Amman, Jordan. His research interests include software testing, computer network, cloud computing. 